\title{
Feature Optimization and Performance Improvement of a Multiclass Intrusion Detection System using PCA and ANN
}

\author{
Ravi Kiran Varma.P \\ MVGR College of Engineering, \\ Vizianagaram, AP, INDIA
}

\author{
V. Valli Kumari \\ Andhra University College of Engineering, \\ Visakhapatnam, AP, INDIA
}

\begin{abstract}
There are several bottle necks in the process of high speed intrusion detection, of which large dimensionality is one of the major problem. We have employed the Principal Component Analysis (PCA) algorithm to handle this problem, through which we have improved the performance of the Artificial Neural Network (ANN) classifier for intrusion detection. With the help of PCA we were able to identify the top 15 out of 41 features among the feature set of KDD cup 1999 data set, and noticed an improvement of over $62 \%$ in the training time of ANN. The Multi Layer Perceptron Neural Network improved the accuracy even after the feature reduction.
\end{abstract}

\section{Key words}

MLP Neural Networks, Principal Component Analysis, Intrusion Detection System.

\section{INTRODUCTION}

Attack detection in a computer network is always a challenge that the security administrators and the personnel face. Intrusion Detection System (IDS) is a primary choice and one among the tools for perimeter security. Among the two major types of IDS i.e. Misuse based and Anomaly based, the Anomaly based IDS has an edge over the other type in detecting novel and ever varying patterns of attacks[17]. Lots of literature and studies go into the use of Artificial Neural Networks (ANN) [12], [13], [16], [21] due to several advantages like good learning ability, adaptability, fault tolerant, hardware implement ability, inherent feature of contextual information processing, low energy consumption etc. In this paper we have proposed a 15 class classifier. Most of the literature is based on KDD 1999 IDS evaluation data standard which consists of 41 features. In this study we have trained and tested our ANN with all the 41 features and also tried to optimize the feature set by reducing the number of features to 15 using Principal Component Analysis (PCA) and further training and testing showed a considerable improvement in training time by $62 \%$.

Related work: J.P Anderson defined the Intrusion attempt in [23] and created a room for several studies on IDS and techniques. Dorothy Denning [10] has inspired many researchers by proposing an anomaly based Intrusion Detection model. The interesting work of Varun Chandola et.al. [8] discusses about various anomaly intrusion detection mechanisms. A similar work done by Fariba Haddadi et.al. [4] demonstrates a five class classifier to detect the intrusions from the DARPA data set where an average of $82.44 \%$ detection rate was reported. In another work [9] a two class classifier based on feed forward neural network was proposed. Neural Network proved to be good for anomaly detection to find user behaviour in [15]. In [3] a Hybrid intrusion detection system was demonstrated. The use of PCA in [24] by Solomon Raju e.al. reduced the complex data set to a lower dimension to reveal hidden structures. In a paper by T.Petreus et.al. [5] PCA was used to extract essential features in the field of bio-informatics. In a study [6] the authors used PCA to detect hidden software features for malware analysis. In [7] the authors Leila Mechtri et.al used PCA and grey neural networks for classification of intrusion data with five classes.. In our present work we have proposed a novel multiclass classifier model which can detect 15 classes of attacks including normal traffic. The optimized features proved to improve the performance on the ANN by reducing the training time and also the detection accuracy.

The section I consists of the motivation and introduction to our work, section II consists of description about Intrusion detection system, types and about the date set selection for the study. Section III consists of description of the Artificial Neural Network model used for this study. Section IV consists of discussion on Principal Component Analysis algorithm and its role in feature optimization of the data set. Section V consists of the result analysis and conclusions.

\section{INTRUSION DETECTION SYSTEM AND THE KDD DATA SET}

\subsection{Intrusion Detection System}

Intrusions Detection Systems still are the hot picks of the security administrators due to several reasons including no system can be completely secure without any flaws or vulnerabilities [11]. The important classes of intrusions include attempted break-ins, penetration of security control systems, information leakage, Denial of Service, Masquerading, Malicious use etc. The IDS can detect most of these types of attacks and help for further study and analysis of these attacks and to patch the security systems. Among the two major types of IDS i.e Anomaly based and Misuse based the Anomaly based IDS has an advantage of detecting novel and even slight variations of the attacks [18]. Artificial Intelligence techniques such as the ANNs, SVM, HMM etc. are often employed for IDS to detect novel attacks. The Multi Layer Perceptron feed forward Neural Network is being used as the IDS algorithm for classification of various types of attacks. The neural network system requires data sets for training, which should include both normal traffic as well as attack traffic. The KDD Cup 1999 IDS evaluation data set is used since it the standard data set for researchers in this area [20].

\subsection{KDD CUP'99 Dataset Description}

KDDCUP'99 is the most widely used dataset for the evaluation of anomaly detection methods. It includes the following attack categories [14]:

\subsubsection{Denial of Service attack $(\mathrm{DoS})$ :}

Here the attacker tries to send some malicious packets, may be tcp, udp, or icmp, to fill up the memory or to make the 
computing resource very busy to handle legitimate users access to a machine.

\subsubsection{U2R (User to Root):}

This is an attack where the hacker tries to gain access to the root account of the target system starting with access to a normal user account, with the help of exploit code or methods that takes advantage of vulnerabilities.

\subsubsection{R2L (Remote to Local):}

In this type of attack, an attacker who does not have any account on that target machine, exploits some vulnerability and tries to gain the access of that target machine.

\subsubsection{Probing Attack:}

Is a class of exploit where the malicious hacker attempt to gather information about a network of computers. [22]

The KDD CUP 99 dataset consists of 41 features for each packet. Table.1 shows the feature description of all the features in KDD CUP 99 dataset. The data set is preprocessed before applying on the ANN to contain only numerical values, but nor string values.

Table 1. KDD Cup 1999 data set features.

\begin{tabular}{|c|c|c|c|}
\hline No. & Features & No. & Features \\
\hline 1. & duration & 22. & Is guest login \\
\hline 2. & protocol type & 23. & count \\
\hline 3. & service & 24. & Srv count \\
\hline 4. & flag & 25. & Serror rate \\
\hline 5. & src bytes & 26. & Srv serror rate \\
\hline 6. & dst bytes & 27. & Rerror rate \\
\hline 7. & land & 28. & Srv rerror rate \\
\hline 8. & wrong fragment & 29. & Same srv rate \\
\hline 9. & urgent & 30. & Diff srv rate \\
\hline 10. & hot & 31. & Srv diff host rate \\
\hline 11. & num failed logins & 32. & Dst host count \\
\hline 12. & Logged in & 33. & Dst host siv count \\
\hline 13. & Num compromised & 34. & Dst host same srv rate \\
\hline 14. & Root shell & 35. & Dst host diff srv rate \\
\hline 15. & Su attempted & 36. & Dst host same src port rate \\
\hline 16. & Num root & 37. & Dst host srv diff host rate \\
\hline 17. & Num file creations & 38. & Dst host serror rate \\
\hline 18. & Num shells & 39. & Dst host srv serror rate \\
\hline 19. & Num access files & 40. & Dst host rerror rate \\
\hline 20. & Num outbound cmds & 41. & Dst host srv rerror rate \\
\hline 21. & Is host login & & \\
\hline
\end{tabular}

\subsection{Data Set Selection for the work:}

The KDD cup 1999 data set [22] consists of two files namely $10 \% \mathrm{KDD}$ and corrected, for heterogeneity in data we took training samples from both of these files as shown in Table.2. For some attack types very limited data sets are available.
Table 2. Number of samples selected from KDD Cup 1999 data set for training and testing.

\begin{tabular}{|c|c|c|c|c|}
\hline $\begin{array}{l}\text { Attac } \\
\mathbf{k} \\
\text { Main } \\
\text { Class }\end{array}$ & $\begin{array}{l}\text { Sub } \\
\text { Class }\end{array}$ & $\begin{array}{l}\text { S. } \\
\text { No } \\
\text { of } \\
\text { CI } \\
\text { ass }\end{array}$ & $\begin{array}{l}\text { No of Data set } \\
\text { taken for } \\
\text { Training } \\
\text { From } 10 \% \\
\text { KDD + From } \\
\text { Corrected. } \\
\end{array}$ & $\begin{array}{l}\text { No. of data } \\
\text { sets taken for } \\
\text { Testing } \\
\text { From } 10 \% \\
\text { KDD + From } \\
\text { Corrected. } \\
\end{array}$ \\
\hline $\begin{array}{l}\text { Norm } \\
\text { al }\end{array}$ & $\begin{array}{l}\text { Norm } \\
\text { al }\end{array}$ & 1 & 15,000 & 15,000 \\
\hline \multirow{5}{*}{$\begin{array}{l}\text { DOS } \\
\text { Attac } \\
\text { ks }\end{array}$} & Smurf & 2 & 25,000 & 25,000 \\
\hline & $\begin{array}{l}\text { Neptu } \\
\text { ne }\end{array}$ & 3 & 15,000 & 15,000 \\
\hline & Back & 4 & 1000 & 1000 \\
\hline & $\begin{array}{l}\text { Mailb } \\
\text { omb }\end{array}$ & 5 & 4000 & 1000 \\
\hline & $\begin{array}{l}\text { Teardr } \\
\text { op }\end{array}$ & 6 & 512 & 412 \\
\hline \multirow{4}{*}{$\mathrm{R} 2 \mathrm{~L}$} & $\begin{array}{l}\text { Snmp } \\
\text { getatta } \\
\text { ck }\end{array}$ & 7 & 5000 & 2000 \\
\hline & $\begin{array}{l}\text { Warez } \\
\text { master }\end{array}$ & 8 & 1020 & 420 \\
\hline & $\begin{array}{l}\text { Guess } \\
\text { _pass } \\
\text { wd } \\
\end{array}$ & 9 & 3050 & 1040 \\
\hline & $\begin{array}{l}\text { Warez } \\
\text { client }\end{array}$ & 10 & 1000 & 500 \\
\hline U2R & $\begin{array}{l}\text { Snmp } \\
\text { guess }\end{array}$ & 11 & 1500 & 500 \\
\hline \multirow{5}{*}{ Probe } & $\begin{array}{l}\text { Ipswe } \\
\text { ep }\end{array}$ & 12 & 800 & 600 \\
\hline & $\begin{array}{l}\text { Ports } \\
\text { weep } \\
\end{array}$ & 13 & 1000 & 700 \\
\hline & Saint & 14 & 600 & 300 \\
\hline & Satan & 15 & 2000 & 1100 \\
\hline & & & 76374 & 65,572 \\
\hline
\end{tabular}

\section{ARTIFICIAL NEURAL NETWORKS 3.1 Artificial Neural Networks}

The main advantages of using ANN is that they posses nonlinearity[2], they provide a input-output mapping by learning with a teacher, they can adapt to the changes in the environment, they provide evidential response, they are fault tolerant, they are VLSI implementable and above all they are neuro-biologically inspired [19]. Among the various types of neural networks the multilayer perceptron (MLPNN) are the best suitable for implementing a multiclass classifier [16].

\subsection{Feed-forward Neural Network:}

The Multilayer feed-forward neural network has several neurons structured in layers such as input, hidden and output layers. Output layer with one or many neurons provides output for one or many inputs. In one neuron example, training process task is to find proper weights for neuron connections which in combination with inputs, achieves the desired output. This process is accomplished by back propagation algorithm.[1] We used Matlab code for running the ANN algorithm, we did not use any tool box for this. 


\subsubsection{The Multi Layer Perceptron Artificial} Neural Network before applying PCA is [41-5-15]

$>$ It contains 41 input neurons for each input feature in the KDD dataset

$>$ Five hidden neurons were selected based on trial and error method

$>$ Fifteen output neurons to determine normal or attack types.

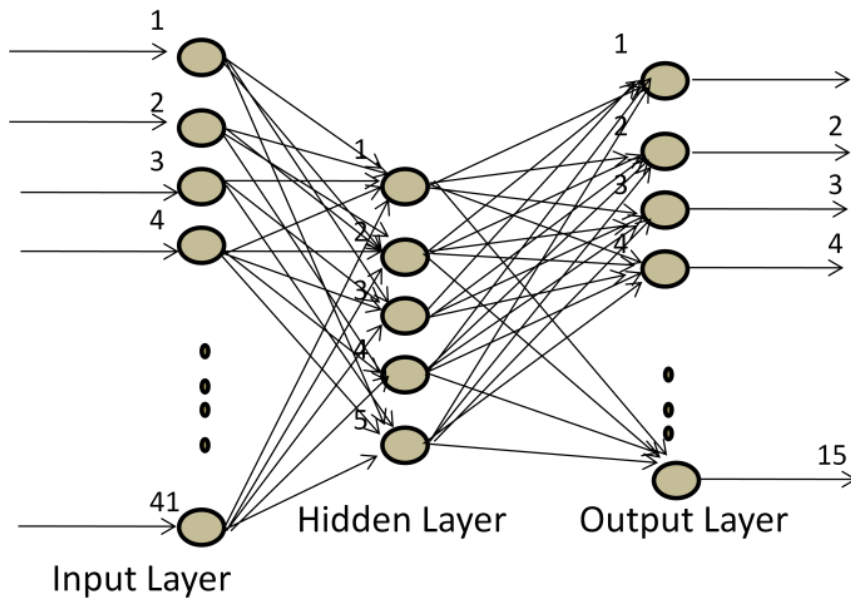

Figure 1. MLPNN Architecture

The Multi Layer Perceptron Artificial Neural Network algorithm is shown below:

\subsubsection{Algorithm :}

\section{STEP 1: START}

STEP 2: Initialize number of hidden neurons and epochs.

STEP 3: Load the pre-processed input data for training.

STEP 4: Generate initial weights of neurons randomly

STEP 5: for $i=1$ to number of ephocs

for $\mathrm{j}=1$ to No. of input patterns

- $\quad$ Select the random pattern

- Calculate the output of hidden layer by using the following formula:

$$
H_{j}=\frac{1}{1+e^{-\sum_{i=0}^{\text {numInput }}}\left(W 1_{i, j} \cdot X_{i}\right)}
$$

-Adjust the weights of hidden layer

- Calculate the output of output layer by using the following formula:

$$
O_{j}=\frac{1}{1+e^{-\sum_{i=0}^{\text {numHidden }}}\left(W 2_{i, j} \cdot H_{i}\right)}
$$

-Calculate the error at output neuron as:

$$
\Delta W_{j}=O_{j}\left(1-O_{j}\right)\left(T_{j}-O_{j}\right)
$$

for all $\mathrm{j}=1$ to num_Hidden, where $\mathrm{T} j$ is corresponding target output.

- Back propagate the error and calculate the errors at hidden units as:

$$
\Delta V_{j}=H_{j}\left(1-H_{j}\right)\left(\Delta w \cdot W 2_{j}\right) \ldots
$$

Adjust the output weights of hidden neurons according to error end loop if error $<0.001$ end loop

STEP 6: STOP

By the end of the training process the weights are frozen and the ANN model is ready.

\section{FEATURE OPTIMIZATION USING PRINCIPLE COMPONANT ANALYSIS}

Feature optimization is done to reduce the redundancy of features. Principal Component Analysis is used for this purpose. In PCA, feature selection is done for selecting a subset of relevant features, thereby improving the performance of the system. By removing most irrelevant and redundant features from the data, feature selection helps improve the performance of learning models.

Using PCA in optimization generates principal components, whose number is less than or equal to the number of actual components. PCA is an Eigen-vector based multi variant. Often, its operation can be thought of as revealing the internal structure of the data in a way which best explains the variance in the data. Given the visualization of the coordinates of a multivariate dataset in a high-dimensional data space (1 axis per variable), PCA can supply the user with a lowerdimensional picture, a "shadow" of this object. This is done by using only the first few principal components so that the dimensionality of the transformed data is reduced. Below is the general formula to compute scores on the first component extracted (created) in a principal component analysis:

$$
C 1=b 11(X 1)+b 12(X 2)+\ldots b 1 p(X p)---(5)
$$

Where

$\mathrm{C} 1=$ the subject's score on principal component 1 (the first component extracted)

$\mathrm{b} 1 \mathrm{p}=$ the regression coefficient (or weight) for observed variable $\mathrm{p}$, as used in creating principal component 1

$\mathrm{Xp}=$ the subject's score on observed variable $\mathrm{p}$.

\subsection{The PCA Algorithm}

STEP 1: Get some data

The 41 features of the collected data from KDD CUP 99 dataset is applied to PCA for feature optimization on its 41 features, which are redundant and correlated.

STEP 2: Subtract the mean

The mean is calculated as shown below:

$$
\bar{X}=\frac{\sum_{i=1}^{n} X_{i}}{n}
$$

Now the mean is subtracted from each dimension from the data set. The mean subtracted is the average across each dimension. The resultant data set with subtracted means will have a mean of zero.

STEP 3: Calculate the covariance matrix

The covariance matrix will be two dimensional since the data is 2 dimensional. Covariance matrix is calculated as:

$$
\operatorname{var}(X)=\frac{\sum_{i=1}^{n}\left(X_{i}-\bar{X}\right)\left(X_{i}-\bar{X}\right)}{(n-1)}
$$

STEP 4: Calculate the Eigen vectors and Eigen values of the covariance matrix

For generating the signal, we can calculate the Eigen vectors and Eigen values for this matrix, since it is a square matrix. STEP 5: Forming a feature vector by choosing the components: 
Depending on the signals it generate, we need to choose the features whose signal value is more and these features are called principal components.

STEP6: Get the new data

By multiplying the obtained components with the old data, we will get the new data.

\section{RESULTS AND CONCLUSION}

\subsection{Results}

Table 3 shows the detection rates and the false positive rate obtained from the 15 class ANN classifier of various classes of attacks before applying PCA and table 6 shows the corresponding confusion matrix. The results clearly show that the detection rate depends on the number of training set available since from Table.1 we can see that the records for some type of attacks like Tear drop, warezmaster, saint etc. are less in number, so as the detection rates. Table.4 shows the output of PCA from which we selected the top 15 features that are more effective.

Table 3. Detection Rate of MLPANN before applying PCA

\begin{tabular}{|l|l|l|}
\hline Attack Type & $\begin{array}{l}\text { Detection } \\
\text { Rate }\end{array}$ & False Positives \\
\hline Normal & 99.53 & 0.470 \\
\hline Smurf (DOS) & 98.76 & 1.24 \\
\hline Neptune (DOS) & 95.42 & 3.28 \\
\hline Back (DOS) & 88.54 & 6.70 \\
\hline Mailbomb (DOS) & 86.91 & 9.62 \\
\hline Teardrop (DOS) & 77.32 & 15.61 \\
\hline Snmpgetattack(R2L) & 90.10 & 7.9 \\
\hline warezmaster(R2L) & 78.24 & 13.21 \\
\hline Guess_passwd(R2L) & 87.21 & 8.43 \\
\hline Warezclient(R2L) & 80.41 & 13.11 \\
\hline snmpguess(U2R) & 81.17 & 12.10 \\
\hline ipsweep(Probe) & 82.87 & 10.25 \\
\hline portsweep(Probe) & 84.32 & 11.21 \\
\hline saint(Probe) & 73.23 & 17.55 \\
\hline satan(Probe) & 90.34 & 5.56 \\
\hline Average & $\mathbf{8 6 . 2 8 \%}$ & \\
\hline
\end{tabular}

Table 4. Top 15 features selected from PCA

\begin{tabular}{|c|c|c|c|}
\hline $\begin{array}{l}\text { Feature } \\
\text { Rank }\end{array}$ & $\begin{array}{l}\text { Feature } \\
\text { number } \\
\text { out of } \\
41 \\
\text { features }\end{array}$ & Feature name & $\begin{array}{l}\text { Output of PCA } \\
\text { Signal value }\end{array}$ \\
\hline 1 & 5 & Src bytes & 9.913595 \\
\hline 2 & 33 & $\begin{array}{l}\text { Dst host srv } \\
\text { count }\end{array}$ & 8.638142 \\
\hline 3 & 32 & Dst host count & 5.380869 \\
\hline 4 & 3 & Service & 5.380742 \\
\hline 5 & 2 & Protocol type & 5.379961 \\
\hline 6 & 4 & Flag & 5.377820 \\
\hline 7 & 29 & Same srv rate & 5.369393 \\
\hline 8 & 34 & $\begin{array}{l}\text { Dst host same } \\
\text { srv rate }\end{array}$ & 5.356421 \\
\hline 9 & 36 & $\begin{array}{l}\text { Dst host same } \\
\text { src port name }\end{array}$ & 5.354023 \\
\hline 10 & 12 & Logged in & 5.306561 \\
\hline 11 & 38 & $\begin{array}{l}\text { Dst host serror } \\
\text { rate }\end{array}$ & 5.288926 \\
\hline 12 & 37 & $\begin{array}{l}\text { Dst host serv } \\
\text { diff host name }\end{array}$ & 5.288926 \\
\hline 13 & 35 & $\begin{array}{l}\text { Dst host diff } \\
\text { serv rate }\end{array}$ & 5.258945 \\
\hline 14 & 1 & Duration & 5.117015 \\
\hline
\end{tabular}

\begin{tabular}{|l|l|l|l|}
\hline 15 & 31 & $\begin{array}{l}\text { Srv diff host } \\
\text { rate }\end{array}$ & 3.201556 \\
\hline
\end{tabular}

Figure. 2 shows the comparison of training times of the ANN before and after applying PCA for feature reduction.

Table 5. Training time of MLPANN for varying number of data sets before and after optimization using PCA

\begin{tabular}{|l|l|l|}
\hline $\begin{array}{l}\text { Number } \\
\text { of } \\
\text { Training } \\
\text { Sets }\end{array}$ & $\begin{array}{l}\text { Training time } \\
\text { before } \\
\text { optimization(In } \\
\text { sec) }\end{array}$ & $\begin{array}{l}\text { Training time } \\
\text { after } \\
\text { optimization(In } \\
\text { sec) }\end{array}$ \\
\hline 50 & 1.2216 & 0.9824 \\
\hline 100 & 1.7521 & 1.3400 \\
\hline 300 & 3.2733 & 1.9654 \\
\hline 500 & 3.8845 & 2.4121 \\
\hline 1,000 & 5.1320 & 3.1120 \\
\hline 5,000 & 8.6560 & 4.2631 \\
\hline 10,000 & 11.5410 & 6.1825 \\
\hline 15,000 & 18.6718 & 8.2123 \\
\hline $1,00,000$ & 62.1300 & 38.9290 \\
\hline
\end{tabular}

Figure 2. Training Time graph for comparison before and after PCA

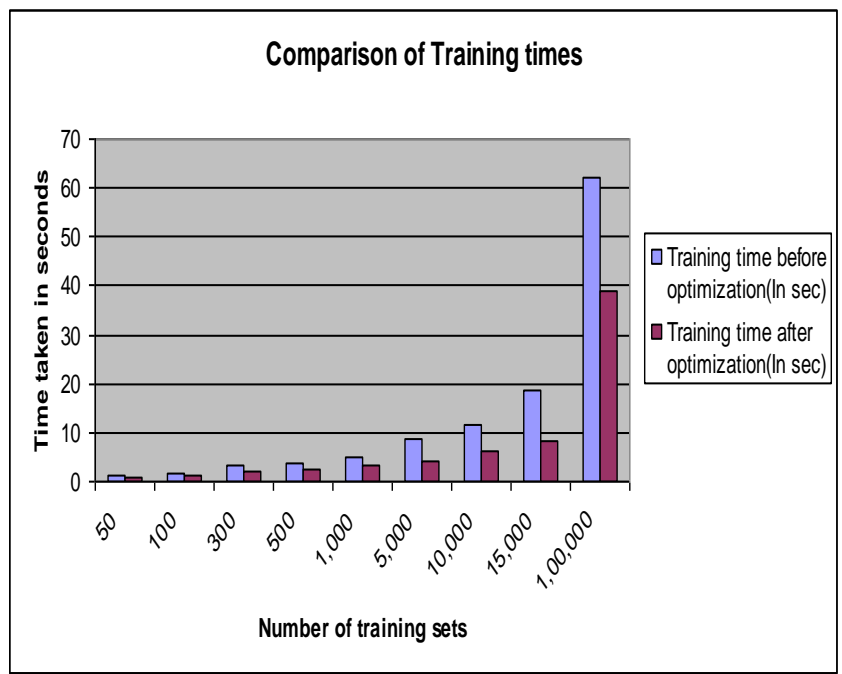

The lower detection rates of few of the classes are due to the fact that the data set for training is very limited.

Table 5. Detection Rate of MLPANN after applying PCA

\begin{tabular}{|l|l|l|}
\hline Attack Type & $\begin{array}{l}\text { Detection } \\
\text { Rate }\end{array}$ & False Positives \\
\hline Normal & 99.61 & 0.39 \\
\hline Smurf (DOS) & 98.58 & 1.42 \\
\hline Neptune (DOS) & 95.81 & 2.83 \\
\hline snmpguess(U2R) & 81.22 & 12.3 \\
\hline ipsweep(Probe) & 84.10 & 9.81 \\
\hline Warezclient(R2L) & 80.29 & 12.76 \\
\hline Snmpgetattack(R2L) & 90.72 & 6.77 \\
\hline warezmaster(R2L) & 80.17 & 11.68 \\
\hline Guess_passwd(R2L) & 87.60 & 8.11 \\
\hline portsweep(Probe) & 85.21 & 10.84 \\
\hline saint(Probe) & 74.54 & 16.65 \\
\hline satan(Probe) & 91.14 & 5.20 \\
\hline Total & $\mathbf{8 8 . 3 1 \%}$ & \\
\hline \hline Back (DOS) & 90.16 & 6.12 \\
\hline Mailbomb (DOS) & 88.13 & 8.64 \\
\hline Teardrop (DOS) & 78.14 & 13.18 \\
\hline
\end{tabular}


Table 6. Confusion Matrix before applying PCA

\begin{tabular}{|c|c|c|c|c|c|c|c|c|c|c|c|c|c|c|c|c|}
\hline $\begin{array}{l}\text { Pred } \\
\text { icted } \\
\text { Actu } \\
\text { al } \\
\end{array}$ & $\begin{array}{l}\text { Nor } \\
\text { mal }\end{array}$ & $\begin{array}{l}\text { smu } \\
\text { rf }\end{array}$ & $\begin{array}{l}\text { neptu } \\
\text { ne }\end{array}$ & $\begin{array}{l}\text { bac } \\
\mathbf{k}\end{array}$ & $\begin{array}{l}\text { Mailb } \\
\text { omb }\end{array}$ & $\begin{array}{l}\text { teard } \\
\text { rop }\end{array}$ & $\begin{array}{l}\text { snmp } \\
\text { getatt } \\
\text { ack }\end{array}$ & $\begin{array}{l}\text { war } \\
\text { ezm } \\
\text { aste } \\
\mathbf{r} \\
\end{array}$ & $\begin{array}{l}\text { Gue } \\
\text { ss_p } \\
\text { assw } \\
\text { d } \\
\end{array}$ & $\begin{array}{l}\text { warez } \\
\text { client }\end{array}$ & $\begin{array}{l}\text { snm } \\
\text { pgu } \\
\text { ess }\end{array}$ & $\begin{array}{l}\text { ipsw } \\
\text { eep }\end{array}$ & $\begin{array}{l}\text { ports } \\
\text { weep }\end{array}$ & $\begin{array}{l}\text { sain } \\
\mathbf{t}\end{array}$ & $\begin{array}{l}\text { Sata } \\
\mathbf{n}\end{array}$ & $\begin{array}{l}\text { Oth } \\
\text { ers }\end{array}$ \\
\hline $\begin{array}{l}\text { Nor } \\
\text { mal }\end{array}$ & $\begin{array}{l}99.5 \\
3\end{array}$ & 0 & 0 & 0 & 0 & 0.12 & 0 & 0 & 0 & 0.05 & 0 & 0 & 0 & 0.21 & 0 & 0.09 \\
\hline $\begin{array}{l}\text { Smu } \\
\text { rf }\end{array}$ & 0 & $\begin{array}{l}98.7 \\
6\end{array}$ & 0 & 0.04 & 0 & 0.2 & 0 & 0.6 & 0 & 0 & 0 & 0 & 0 & 0.12 & 0 & 0.28 \\
\hline $\begin{array}{l}\text { Nept } \\
\text { une }\end{array}$ & 0 & 0 & 95.42 & 0.04 & 0.01 & 0.3 & 0.1 & 2.03 & 0.3 & 0 & 0 & 0.21 & 0 & 0 & 0.5 & 1.09 \\
\hline Back & 0.4 & 0.22 & 0.63 & $\begin{array}{l}88.5 \\
4\end{array}$ & 0.21 & 2.11 & 0.31 & 3.02 & 0.44 & 0.31 & 0.4 & 0.3 & 0.6 & 1.01 & 0.22 & 1.28 \\
\hline $\begin{array}{l}\text { Mail } \\
\text { bom } \\
\text { b } \\
\end{array}$ & 0.5 & 1.03 & 1.21 & 0.6 & 86.91 & 1.87 & 0.3 & 2.54 & 1.13 & 0.91 & 0.31 & 0.45 & 0.33 & 0.71 & 0 & 1.2 \\
\hline $\begin{array}{l}\text { Tear } \\
\text { drop }\end{array}$ & 1.93 & 1.64 & 0.45 & 1.12 & 1.44 & 77.32 & 1.13 & 4.01 & 2.16 & 0.54 & 0.32 & 0.53 & 1.12 & 3.89 & 0.13 & 2.27 \\
\hline $\begin{array}{l}\text { Snm } \\
\text { pget } \\
\text { attac } \\
\text { k }\end{array}$ & 0.06 & 0.54 & 0.33 & 1.02 & 0.21 & 2.32 & 90.10 & 2.14 & 0.76 & 0.44 & 0.06 & 0.41 & 0.05 & 0.32 & 0 & 1.24 \\
\hline $\begin{array}{l}\text { ware } \\
\text { zmas } \\
\text { ter }\end{array}$ & 2.12 & 2.08 & 1.76 & 2.23 & 2.74 & 4.87 & 1.14 & $\begin{array}{l}78.2 \\
4\end{array}$ & 1.02 & 0.57 & 0.69 & 0.11 & 0.44 & 1.53 & 0.03 & 0.43 \\
\hline $\begin{array}{l}\text { Gues } \\
\text { s_pa } \\
\text { sswd }\end{array}$ & 0.56 & 1.12 & 0.74 & 0.52 & 1.07 & 0.02 & 1.12 & 2.69 & $\begin{array}{l}87.2 \\
1\end{array}$ & 1.87 & 1.64 & 0.01 & 1.01 & 0.21 & 0.02 & 0.19 \\
\hline $\begin{array}{l}\text { War } \\
\text { ezcli } \\
\text { ent }\end{array}$ & 1.37 & 0.25 & 1.63 & 1.58 & 1.24 & 1.13 & 0 & 2.86 & 2.13 & 80.41 & 1.33 & 0.45 & 0.63 & 2.59 & 1.11 & 1.29 \\
\hline $\begin{array}{l}\text { snm } \\
\text { pgue } \\
\text { ss } \\
\end{array}$ & 2.25 & 1.81 & 1.66 & 0.53 & 0.22 & 2.98 & 0.19 & 0.77 & 1.47 & 1.13 & $\begin{array}{l}81.1 \\
7\end{array}$ & 0.25 & 0.66 & 1.99 & 0.74 & 2.18 \\
\hline $\begin{array}{l}\text { ipsw } \\
\text { eep }\end{array}$ & 0.65 & 0.73 & 1.66 & 1.12 & 1.31 & 2.07 & 1.05 & 2.13 & 1.76 & 1.13 & 1.88 & $\begin{array}{l}82.8 \\
7\end{array}$ & 0.88 & 0.66 & 0 & 0.1 \\
\hline $\begin{array}{l}\text { ports } \\
\text { weep }\end{array}$ & 0 & 0.04 & 1.66 & 1.13 & 0.53 & 0.62 & 1.14 & 1.93 & 1.65 & 1.13 & 0.66 & 0.84 & 84.32 & 2.11 & 0.05 & 2.19 \\
\hline saint & 3.14 & 2.11 & 2.54 & 1.66 & 1.48 & 2.45 & 3.28 & 3.11 & 0.76 & 0.98 & 1.52 & 1.44 & 0.43 & $\begin{array}{l}73.2 \\
3\end{array}$ & 0.08 & 1.79 \\
\hline $\begin{array}{l}\text { sata } \\
\text { n }\end{array}$ & 0 & 0 & 0.42 & 0.66 & 1.72 & 0.91 & 0.02 & 1.66 & 0.49 & 0.31 & 1.84 & 0.13 & 0.48 & 0.02 & $\begin{array}{l}90.3 \\
4\end{array}$ & 1 \\
\hline
\end{tabular}

\subsection{CONCLUSION}

Our results show that Principal Component Analysis proved to be a very efficient technique that can be used for data dimensionality reduction without the loss of the originality of the data set. The MLP neural network has proved to implement a multiclass classification problem very efficiently even with 15 classes. In this work we have demonstrated the capability of ANN in a detailed outlier classifications related to Intrusion Detection Systems data set. Table 5 shows the improvement of $62 \%$ in the training efficiency regarding the time consumed, which is a very significant improvement.

\section{REFERENCES}

[1] Ravi Kiran Varma.P, V.Valli Kumari, VVS. Prasanna, "Heuristic approach to improve the performance of ANN based Intrusion Detection System ", Proceedings of the $3^{\text {rd }}$

IEEE International Conference on Signal Processing Systems, August 2011, Yantai, China, pp 071-076, 2011

[2] Kachurka P, Golovko V, "Neural Network Approach to real time network intrusion detection and recognition", IEEE $6^{\text {th }}$ International Conference on Intelligent Data Acquisition and Advanced Computing Systems, September 2011, Czech Republic, pp 393-397, 2011

[3] Amza C, Leordeanu C, Cristea V, "Hybrid Network Intrusion Detection", Proceedings of the 2011 IEEE International Conference on Intelligent Computer Communication and Processing, pp 503-510, Romania, Aug 2011.

[4] Fariba Haddadi, Sara khanchi, Mehran Shetabi, Vali Derhami "Intrusion detection and attack classification using Feed-Forward Neural Network", Proceedings of the Second IEEE International Conference on Computer and Network Technology, Thailand, pp 262-266, April 2010

[5] T.Petreus, CE Cotrutz, M. Neamtu, E.C. Buruiana, P.D. Sirbu, A. Neamtu, "Understanding the dynamics-activity relationship in metalloproteases : Idea for new inhibition strategies", 2010 IEEE International Conference on Advanced Technologies for Enhancing Quality of Life, pp 83-86, Romania, Dec 2010.

[6] Jason L Wright, Milos Mamic, "The Analysis of Dimensionality Reduction techniques in Cryptographic Object Code Classification", IEEE International Conference 
on Human System Interaction,pp 157-162, Poland, May 2010 .

[7] Leila Mechtri, Fatiha Djemili Tolba, Nacira Ghoualmi, "Intrusion Detection Using Principal Component Analysis", IEEE $2^{\text {nd }}$ International Conference on Engineering Systems Management and its Applications, pp 1-6, France, Aug 2010.

[8] Varun Chandola, Arindam Banerjee, Vipin Kumar, "Anomaly Detection: A Survey", ACM Computing Surveys, Vol. 41, No. 3, Article 15, July 2009.

[9] Yana Demidova, Maksym Ternovoy, "Neural Network Approach of Attack's Detection In the Network Traffic", The IXth International Conference "The Experience of Designing and Application of CAD Systems in Microelectronics" Feb 2007 IEEE, Ukraine, pp128-129, 2007

[10] D. E. Denning, "An intrusion detection model," IEEE Transactions on Software Engineering, vol. 13, no. 2, pp. 222-232, 1987.

[11]. J. Ryan, M. Lin and R. Miikkulainen, Intrusion Detection with Neural Networks, AI Approaches to Fraud Detection and Risk Management: Papers from the 1997 AAAI Workshop, Providence, RI, pp. 72-79, 1997.

[12] K. Fox, R. Henning, J. Reed and R. Simonian, A Neural network approach towards intrusion detection, Proceedings of ACM 13th National Computer Security Conference, Baltimore, MD, pp. 125-134, 1990.

[13] James Cannady, Artificial neural networks for misuse detection, Proceedings of the 1998 National Information Systems Security Conference (NISSC'98), Arlington, VA, 1998

[14]D.Nagaraju, P.Srinivasulu, V.Valli Kumari, A.Govardhan, "Outlier detection as network intrusion detection system using multilayered framework" proceedings of the Springer CCSIT 2011, pp 101-111, 2010.

[15] H. Debar, M. Becker, and D. Siboni, A neural network component for an intrusion detection system, Proceedings of 1992 IEEE Computer Society Symposium on Research in
Security and Privacy, Oakland, California, pp. 240 - 250, 1992.

[16] M. Moradi, Mohammad Zulkernine. A Neural Network Based System for Intrusion Detection and Classification of Attacks. Proceedings of 2004 IEEE International Conference on Advances in Intelligent Systems - Theory and Applications, Luxembourg-Kirchberg, Luxembourg, 2004.

[17] John McHugh, Alan Christie, Julia Allen, "Defending Yourself: The role of Intrusion Detection Systems", IEEE Software, vol 17 no. 5 pp 42-51, Sep 2000.

[18] Iftikhar Ahmad, Azween B Abdullah, Abdullah S Alghamdi "Application of artifitial neural networks in detection of DOS attacks", Proceedings of ACM SIN'09, North Cyprus, Turkey, 2009.

[19] S.Mukkamala, G. Janoski, A.H.Sung, "Intrusion Detection Using Neural Networks and Support Vector Machines", Proceedings of IEEE International Joint Conference on Neural Networks (Hawaii, May 2002) pp 1702-1707, 2002

[20]Amit kumar Choudary, Akhilesh Swarup, "Neural Network Approach for Intrusion Detection", proceedings of the 2009 International Conference of Interaction Sciences, Seoul, Korea, 2009

[21] Srinivas Mukkamala, Intrusion detection using neural networks and support vector machine, Proceedings of the 2002 IEEE International Honolulu, HI, 2002.

[22]KDD 1991 datasets. The UCI LDD Archive, http://kdd.ics.uci.edu/databases/kddcup99/kddcup99.html, Irvine, CA, USA, 1999.

[23] J.P Anderson. Computer Security Threat Monitoring and Surveillance. Technical report, James P Anderson Co., Fort Washington, Pennsylvania, April 1980.

[24] Solomon Raju Kota, J.L. Raheja, Ashutosh Gupta, Archana Rathi, Shashikant Sharma, "Principal Component Analysis for Gesture Recognition using System C", 2009 IEEE International Conference on Adcances in Recent Technologies in Communication and Computing", pp 732737, India, October 2009. 